\title{
Reproduction of ablated and unablated Penaeus schmitti in captivity using diets consisting of fresh-frozen natural and dried formulated feeds
}

\author{
Iracema Andrade Nascimento ${ }^{a}$, William A. Bray ${ }^{b}$, Joanna R. Leung Trujillo \\ and Addison Lawrence ${ }^{\mathrm{b}}$ \\ anstitute of Biology. Federal University of Bahia, Ondina 40.210, Salvador, Bahia, Brazil \\ ${ }^{b}$ Shrimp Mariculture Project. Texas Agricultural Experiment Station, Texas A\&M University, \\ P.O. Drawer Q. Port Aransas, TX 78373, USA
}

(Accepted 24 February 1991)

\begin{abstract}
Nascimento, I.A., Bray, W.A., Leung Trujillo, J.R. and Lawrence, A., 1991. Reproduction of ablated and unablated Penaeus schmitti in captivity using diets consisting of fresh-frozen natural and dried formulated feeds. Aquaculture, 99: 387-398.
\end{abstract}

Reproduction of Penaeus schmitti was achieved in a recirculating seawater system using three different diets: $100 \%$ fresh-frozen, $50 / 50 \%$ fresh-frozen/dried and $100 \%$ dried formulated feeds. Shrimp fed the $50 / 50 \%$ fresh-frozen/dried and $100 \%$ dzied diets had significantly higher $(P<0.05)$ spawning rates $(0.729 /$ day $)$ than those fed $100 \%$ fresh-frozen food $(0.446 /$ day $)$. Ablation of one eyestalk enhanced female maturation under mixed $(+245 \%)$ and fresn-frozen $(+548 \%)$ diets, but did not influence spawn size nor spawn frequency. Spawn size did not decline during the 2-month study, but spawn frequency and number of mar ngs were reduced toward the end of the period. Diet influenced all $\boldsymbol{P}$. schmitti reproductive processes which were monitored during the study. One hundred percent dried formulated feed induced the best maturation, spawning and fecundity. Results using the mixed diet were slightly lower, but did not differ significantly $(P>0.05)$. The mixed and $100 \%$ fresh-frozen diets induced significantly higher $(P<0.05)$ molting ( 1.525 vs. $0.940 /$ day) and mating $(0.080$ vs. $0.000 /$ day) frequencies than the $100 \%$ dried diet. Considering the relative importance of all of these parameters, we conclude that the mixed diet led to the best results. The lunar cycle influenced moiting and mating. Mating peaked during full and new moens while molting generally occurred between these periods.

\section{INTRODUCTION}

In Brazil, Penaeus schmitti is considered to be one of the most suitable species for culture. Under extensive cultivation, in ponds where salinity ranges from 20 to $45 \mathrm{ppt}$, it grows to a larger size than other native species. The major impediments to the commercial utilization of $P$. scrmitti have been: 1 . the shortage and unpredictability of wild postlarvae for stocking; 2 . the lack 
of an assured supply of wild spawners for projects which have no maturation facilities; and 3. the difficulty in inducing mature shrimp to mate in captivity.

Although reproduction of penaeid shrimp in captivity has been accomplished at various facilities around the world (Alikunhi et al., 1975; Arnstein and Beard, 1975; Aquacop, 1975, 1976, 1979; Laubier-Bonichon and Laubier, 1976; Nurjana and Yang, 1976; Beard et al., 1977; Santiago, 1977; Lichatowich et al., 1978; Brown et al., 1979; Lumare, 1979; Primavera et al., 1979, 1980; Beard and Wickins, 1980; Emmerson, 1980; Kelemec and Smith, 1980; Lawrence et al., 1980; San Feliu, 1987), in many cases it is difficult to get reproducible results in view of the poor understanding of the requirements of maturaiion, mating and spawning, especially for open-thelycum shrimp. In the majority of successful attempts, maturation of penaeid shrimp in captivity was accomplished through unilateral eyestalk ablation (Nurjana and Yang, 1976; Aquacop, 1979; Lumare, 1979; Beard and Wickins, 1980; Emmerson, 1980), although some disadvantages of ablation, such as lower fecundity and hatching rates and shorter period of viable spawning have been demonstrated (Aquacop, 1979; Beard and Wickins, 1980). Even though the optimum levels of the variables affecting reproduction of penaeid shrimp are unknown for many species, the control of nutrition, temperature, salinity, $\mathrm{pH}$, light and density, in some cases has resulted in maturation, mating and spawning without ablation (Laubier-Bonichon and Laubier, 1976; Aquaccp, 1979; Emmerson, 1980; Primavera et al., 1980).

Although nutrition is considered one of the most important factors in reproduction, little research has been conducted to evaluate the relative suitability of various food types, especially for maturation. Based on the following studies, mixed diets of different natural fresh-frozen food or combinations of fresh-frozen food and dried formulated feed are better than a single food (Arnstein and Beard, 1975; Aquacop, 1975, 1979; Beard et al., 1977; Santiago, 1977; Brown et al., 1979; Primavera et al., 1979; Beard and Wickins, 1980; Emmerson, 1980; Kelemec and Smith, 1980; Lawrence et al., 1980) even though successfully induced maturation has been accomplished for some penaeids using a single food organism (Alikunhi et al., 1975; Laubier-Bonichon and Laubier, 1976; Nurjana and Yang, 1976; Lichatowich et al., 1978; Lumare, 1979; Primavera, 1978). The effect of a nonsupplemented, prepared-feed diet on reproduction has not yet been reported.

None of these studies has focused on Penaeus schmitti. Consequently, our study was undertaken to determine the influences of varied diets on the reproduction of ablated and unablated $P$. schmitti in the laboratory.

\section{MATERIALS AND METHODS}

The research was conducted in the Maturation/Reproduction Laboratory of the Texas A\&M University Mariculture Facility, located near the Barney M. Davis Power Station in Corpus Christi, Texas. 
Water coming from the Laguna Madre was pumped from the settling pond into the Maturation/Reproduction Laboratory which housed 16 light blue fiberglass tanks ( $3.7 \mathrm{~m}$ diameter $\times 0.9 \mathrm{~m}$ depth ). A $30-\mathrm{cm}$-high plastic net was attached to the upper edge of each tank to retain jumping shrimp.

In order to maintain adequate water quality with minimal water exchange ( $15 \% /$ week), each tank was connected to a common recirculating water system. Water exited from each maturation tank via a central standpipe which regulated water level at about $60 \mathrm{~cm}$. This waste water flowed into a reservoir tank, where it was treated with a foam fractionator to remove excess dissolved organic material. Waste water was then pumped at a rate of $3761 / \mathrm{min}$ through a sand filter, and sprayed over a biological bed of $1-\mathrm{cm}$ plastic pellets. From the biological filter, the water was pumped through another sand filter, before being returned to the tanks. The entire system had a capacity of 108880 1 of water. Repiacement seawater for the recirculating system was held for 2 days in a settling tank located indoors, where it could be warmed during the winter by four space heaters $(20 \mathrm{~kW}$ total $)$.

Each maturation tank was equipped with aeration. Lighting was provided with blue fluorescent bulbs (Model F40T12/6, GTE Products Corporation, Sylvania Lighting Products, Danvers, MA) masked to provide approximately $12 \mu$ Watts $\mathrm{cm}^{2} \mathrm{~s}^{-1}$ at the water surface. The photoperiod of these lamps was set by automatic timers to deliver $14 \mathrm{~h}$ of light and $10 \mathrm{~h}$ of darkness. Square, flat-bottomed $250-1$ fiberglass tanks $(91 \times 91 \times 36 \mathrm{~cm})$ nitted with a plywood cover and five airstones (with weak aeration) were used as spawning containers. Each spawning tank was painted black, with the exception of a translucent $3 \times 4 \mathrm{~cm}$ patch on one side just below the water level mark. Phototactic collection of larvae was accomplished by ceasing aeration and directing a weak light through the translucent patch.

$P$. schmitti specimens weighing $35-40 \mathrm{~g}$ were captured from the wild on the coast of Belize and transported to the maturation facility at Flour Bluff where they were maintained for 4 days in maturation tanks with a flow-through water exchange rate of at least $100 \%$ /day. During this period, they were fed frozen squid mantle ad libitum. The experiment was performed in six maturation tanks using three diet combinations (Table 1).

The species utilized as fresh diet were Crassostrea sp (oyster), Penaeus sp (juvenile shrimp), Glycera dibranchiata (blood worm) and Loligo spp (squids). The dry diet was formulated to contain $65 \%$ protein, $6 \%$ lipid plus vitamin/mineral supplement. The ration formulation will be reported elsewhere.

Each tank held 40 animals with $1: 1$ female to male ratio. Half the females in each tank were ablated according to the method of Primavera (1978). Males in one tank per treatments (nos. 1,3 and 5) were unilaterally ablated. Temperature, salinity, dissolved oxygen, and $\mathrm{pH}$ were measured every morning in each tank. Values for total $\mathrm{NH}_{4}$ and nitrite for individual tanks were taken 
TABLE 1

Experimental feeding regime for reproduction of Penaeus schmitti

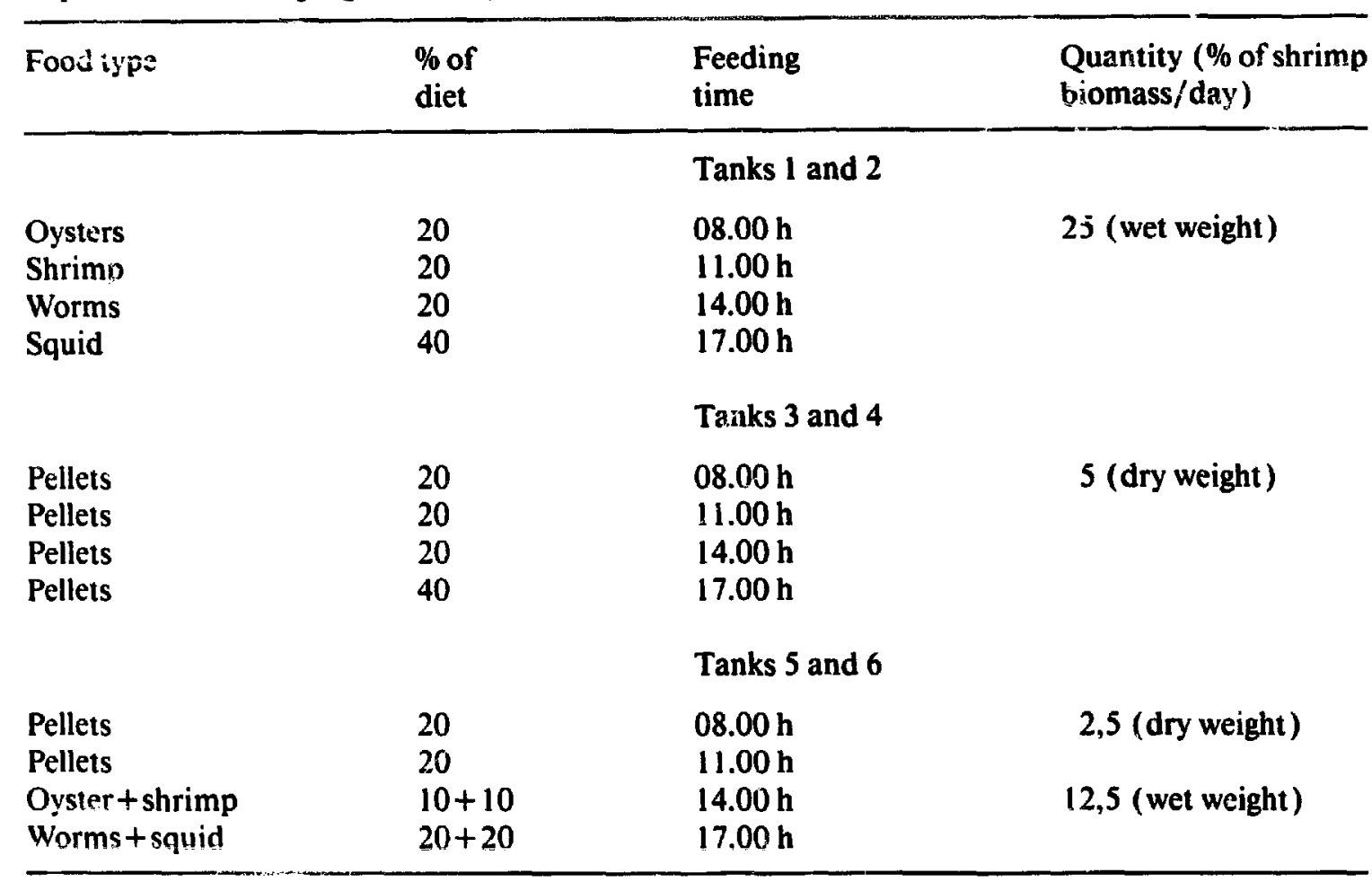

twice per week, decreasing to once per week. Nitrate was ineasured at the end of the study.

Exuviae were removed daily and recorded. Dead shrimps in each tank were recorded by sex and size. One week after the start of the experiment, a finemesh bag was attached to the discharge of an airlift within each tank to detect the presence of eggs and nauplii. When the first fertile spawn was observed, evaluations of maturation and mating were initiated at a rate of three/ week, increasing to every night, after 2 weeks. These evaluations were made by using a 200 000-candle-power spotlight as described by Chamberlain and Lawrence (1981). Only stages III and IV of the five-stage classification adapted by King ( 1948 ) were distinguished. Females with stage-IV ovaries were gently netted from the tanks and checked for mating (the presence of an external spermatophore or of a sperm mass between the third pair of pereiopods).

Mated shrimp were removed from the maturation tanks and placed in individual spawning tanks. The disodium salt of EDTA and erythromycin and minocycline were added to the spawning water in concentrations of $0.01 \mathrm{~g} / 1$, $0.18 \mathrm{mg} / \mathrm{l}$ and $0.09 \mathrm{mg} / \mathrm{l}$, respectively. Aeration within spawning tanks was leduced to a minimum. The following morning the females were removed from the spawning tanks, measured for total length and tagged with a numbered plastic band around one eyestalk. They then were returned to their re- 
spective maturation tanks. The number of eggs per spawn was estimated by thoroughly mixing the water within a spawning tank with a paddle and drawing five random samples with a 10-ml Hensen-Stempel pipette. The same sampling procedure was followed the second day to determine the number of nauplii per spawn.

In an attcmpt to improve results of maturation, mating and spawning after 6 weeks, all femaies were ablated and animals from each replicate were joined. In addition, recently captured males were used to artificially inseminate the females.

Descriptive statistics were computed for the daily hydrological data in each tank and for fecundity of ablated and unablated females fed fresh-frozen food, mixed diets and aried formulated feed.

Variation in reproductive performance (maturation, mating and spawning) related to lunar cycle, ablation, diets and periods of observation (three consecutive periods of 15 days starting on 3 March, ending on 30 April) were analysed by correlation analysis, analysis of variance (ANOVA) and the Duncan multiple-range test for comparison of means (Nie et al., 1975). For ANOVA, daily observations were considered as replicates, and the mean number of observations per day was calculated. Theoretically, the observations among days in the same tank were not independent, but if one assumes that the interactions between days were the same for all treatments, ANOVA should be a reasonable measure of differences among treatments.

An angular transformation sin 0 to represent lunar phases was used with minimum values $\left(\sin 0^{\circ}=0.000\right.$ ) for full and new moons and maximum values for quarter moons. Using the absolute value of the sin in all cases and considering the complete lunar cycle (full moon to fuli moon) as $360^{\circ}$, the transformed function closely paralleled the biological parameters observed.

\section{RESULTS}

Variations of hydrological parameters did not differ significantly among tanks. Temperature averaged $27.5^{\circ} \mathrm{C}$ and ranged from 22.5 to $29.2^{\circ} \mathrm{C}$. Salinity varied from 29 to $33 \mathrm{ppt}$, averaging $30.3 \mathrm{ppt}$ in all treatments. Dissolved oxygen concentration averaged $5.8 \mathrm{ppm}$ and varied from 4.2 to $6.4 \mathrm{ppm}, \mathrm{pH}$ averaged 7.9, ranging from 7.7 to 8.1. Average value for total $\mathrm{NH}_{4}-\mathrm{N}$ was 0.12 ppm (range of 0.00 to 0.39 ). The values for nitrite averaged $0.06 \mathrm{ppm}$ in all treatments and nitrate varied from 35.6 to $37.6 \mathrm{ppm}$ for all treatments.

There was no significant mortality of broodstock after unilateral eyestalk ablation. Four days after ablation and stocking there were signs of ovarian maturation in all ireatments. Ablated females matured at a higher frequency (occurrence of stage IV) than unablated ones, in both fresh-frozen and mixed diet treatments $(P<0.001)$. However, occurrence of ablated and unablated stage-IV females was not significantly different within the dry-diet treatment 
(Table 2 ). Significantly fewer $(P<0.05)$ ablated and unablated stage-IV females occurred in the $100 \%$ fresh-frozen-food treatment than in the mixedor dry-diet treatments. Among treatments, ablated stage-IV females occurred at significantly greater frequency $(P<0.05)$ in the mixed- and dry-diet treatments.

Duration of captivity (periods of observation) and lunar cycle also influenced reproductive performance. Maturation of ablated females significantly declined during the course of the study, while maturation of unablated females did not. Maturation of ablated females was correlated $(P<0.1)$ with the lunar cycle, but maturation of unablated females was not $(P=0.05)$.

Dietary treatments influenced mating $(P<0.05)$ as indicated by the presence of egg-nauplii and mated females in tanks receiving fresh-frozen feed, and the absence of mating signs in tanks receiving $100 \%$ dried formulated teed (Table 3 ). The effects of fresh-frozen and mixed diets were similar, with matings occurring in $8 \%$ and $7 \%$ of the fernales, respectively, during the 50 day experimental period. Ablation of males fed the mixed diet (tank 5) seemed to have a negative offect on mating in this treatment (Table 3 ). There was no significant difference $(P>0.05)$ in mating between ablated and unablated males fed the fresh-frozen diet (Table 3 ). There was a significant re-

TABLE 2

Basic statistical data of maturation occurrence (spawns/day at stage IV) for ablated and unablated females, considering the complete experimental period, from 16 March to 21 May. Comparisons between ri,eans within each diet were made with Student $t$-test

\begin{tabular}{|c|c|c|c|c|c|c|c|}
\hline \multirow[t]{2}{*}{ Diet } & \multirow[t]{2}{*}{ Condition } & \multicolumn{6}{|c|}{ Statistics } \\
\hline & & $N$ & $\begin{array}{l}\text { Mean } \\
\text { stage IV }\end{array}$ & $\begin{array}{l}\text { Standard } \\
\text { error }\end{array}$ & Minimum & Maximum & $P$ \\
\hline Fresh-frozen & $\begin{array}{l}\text { Ablated } \\
\text { Unablated }\end{array}$ & $\begin{array}{l}68 \\
68\end{array}$ & $\begin{array}{l}0.382 \\
0.059\end{array}$ & $\begin{array}{l}0.065 \\
0.029\end{array}$ & $\begin{array}{l}0.000 \\
0.000\end{array}$ & $\begin{array}{l}2.000 \\
1.000\end{array}$ & $<0.001$ \\
\hline Mixed & $\begin{array}{l}\text { Ablated } \\
\text { Unablated }\end{array}$ & $\begin{array}{l}70 \\
70\end{array}$ & $\begin{array}{l}0.886 \\
0.257\end{array}$ & $\begin{array}{l}0.107 \\
0,063\end{array}$ & $\begin{array}{l}0.000 \\
0.000\end{array}$ & $\begin{array}{l}4.000 \\
3.000\end{array}$ & $<0.001$ \\
\hline Dried & $\begin{array}{l}\text { Ablated } \\
\text { Unablated }\end{array}$ & $\begin{array}{l}69 \\
65\end{array}$ & $\begin{array}{l}0.551 \\
0.435\end{array}$ & $\begin{array}{l}0.081 \\
0.076\end{array}$ & $\begin{array}{l}0.000 \\
0.000\end{array}$ & $\begin{array}{l}2.000 \\
2.000\end{array}$ & 0.2 \\
\hline
\end{tabular}

\section{TABLE 3}

Multiple-range test of $P$. schmitic daily matings per tank. Means with the same superscript do not differ significantly $(P>0.05)$

\begin{tabular}{lllllll}
\hline Diet & Dried & Dried & Mixed & Fresh-frozen & Fresh-frozen & Mixed \\
Tank & 3 & 4 & 5 & 2 & 1 & 6 \\
Mean & $0.000^{\mathrm{a}}$ & $0.000^{\mathrm{a}}$ & $0.000^{\mathrm{a}}$ & $0.064^{\mathrm{ab}}$ & $0.106^{\mathrm{b}}$ & $0.149^{\mathrm{b}}$ \\
\hline
\end{tabular}


duction $(P<0.05)$ in mating over time (Table 4$)$. The daily occurrence of spawning (Table 5$)$ was significantly different $(P<0.05)$ between treatments, the highest incidences occurring among shrimp fed the mixed and dried diets. The values showed a periodicity and a significant relationship $(P<0.05)$ with the lunar cycle, with the lowest spawning occurrence during the first 15 days of the experiment. There were no significant differences $(P>0.05)$ in spawn size between unilaterally ablated and unablated females and spawn size did not decrease with time. Average spawn sizes were 166555 and 182000 eggs/spawn for ablated and unablated females, respectively.

The mean daily molting frequency for the different treatments, ranged from 0.90 to 1.78 and was found to be significantly different $(P<0.05)$ among diets, the dried formulated feeds (tanks 3 and 4) giving the lowest results (Table 6). There were no significant differences $(P>0.05)$ among shrimps fed fresh-frozen or mixed diets. The total number of molts decreased with time in all treatments (Table 7). There was a strong correlation between daily number of molts and the lunar cycle $(r=0.405 ; P<0.00005)$. The relationships between molting, mating and spawning with the lunar cycle are shown in Fig. 1. While spawning peaks are not evident, molting and mating peaks seem to occur alternately, the mating during full and new moons, and molts in the intervals.

\section{TABLE 4}

Multiple-range test of $P$. schmitti daily mati'gs over all treatments, per experimental period. Means with the same superscripi do not differ significantly $(P>0.05)$

\begin{tabular}{llll}
\hline Period $^{1}$ & 3 & 2 & 1 \\
Mean & $0.011^{\mathrm{a}}$ & $0.056^{\mathrm{ab}}$ & $0.125^{\mathrm{b}}$
\end{tabular}

'Period I: 1 st to 15 th day; Period 2: 16th to 30th day; Period 3: 31th to 45th day.

TABLE 5

Multiple-range test of $P$. schmitti daily spawnings in relation to diets. Means with the same superscript do not differ significantly $(P>0.05)$

\begin{tabular}{lllllll}
\hline Diet & Fresh-frozen & Fresh-frozen & Mixed & Dried & Dried & Mixed \\
Tank & 1 & 2 & 6 & 4 & 3 & 5 \\
Mean & $0.435^{\mathrm{a}}$ & $0.456^{\mathrm{a}}$ & $0.609^{\mathrm{ab}}$ & $0.674^{\mathrm{bc}}$ & $0.783^{\mathrm{bc}}$ & $0.848^{\mathrm{c}}$ \\
\hline
\end{tabular}

TABLE 6

Multiple-range test of $P$. schmitti daily molting occisrence per maturation tank. Means with the same superscript do not differ significantly $(P>0.05$;

\begin{tabular}{lllllll}
\hline Diet & Dried & Dried & Fresh-frozen & Mixed & Mixed & Fresh-frozen \\
Tank & 3 & 4 & 2 & 6 & 5 & 1 \\
Means & $0.900^{\mathrm{a}}$ & $0.980^{\mathrm{ab}}$ & $1.260^{\mathrm{abc}}$ & $1.360^{\mathrm{abc}}$ & $1.700^{\mathrm{bc}}$ & $1.780^{\mathrm{c}}$ \\
\hline
\end{tabular}




\section{TABLE 7}

Multiple-range test of $P$. schmitti daily molting occurrence per diet and experimental period. Means with the sam? sunerscript do not differ significantly $(P>0.05)$

\begin{tabular}{llll}
\hline Diet & Lry & Fresh-frozen & Mixed \\
\cline { 2 - 4 } Mean & $0.940^{\mathrm{a}}$ & $1.520^{\mathrm{b}}$ & $1.530^{\mathrm{b}}$ \\
Period' & 3 & 2 & 1 \\
\cline { 2 - 4 } Mean & $0.878^{\mathrm{a}}$ & $1.400^{\mathrm{ab}}$ & $1.767^{\mathrm{t}}$ \\
\hline
\end{tabular}

1 Period 1: Ist to 15th day; Period 2: 16th to 30th day; Period 3: 31 th to 45th day.

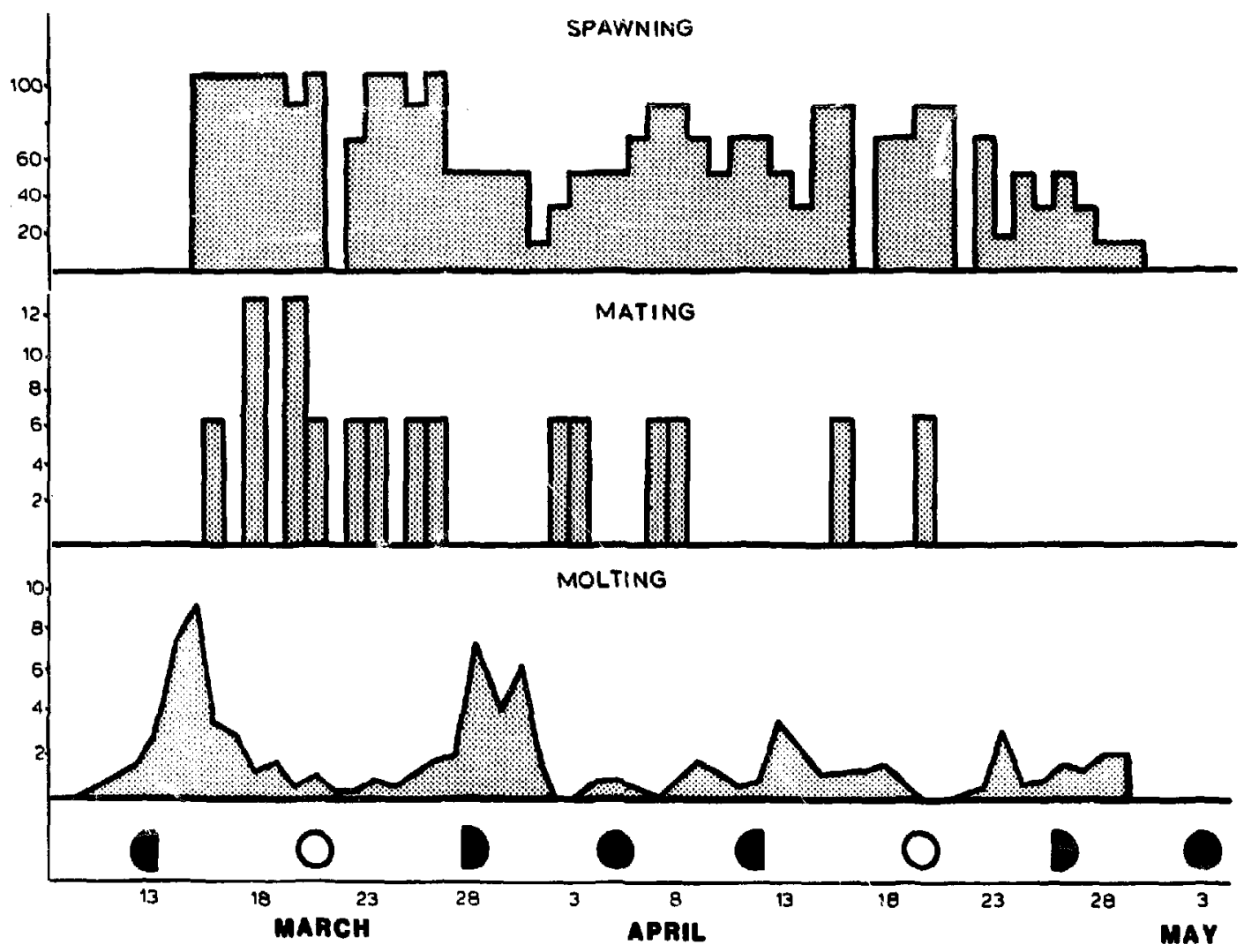

Fig. 1. Occurrences of molting, mating and spawning of $P$. schmitti in relation to the lunar cycle.

Attempts to improve reproductive performance after 2 months of trials did not succeed. Ablation of the remaining unablated females in all treatments after 2 months did not appreciably improve maturation, mating or spawning. Artificial insemination of unilaterally ablated females maintained in the laboratory for 2 months, using spermatophores from males recently captured from the wild, resulted in the production of few viable nauplii ( $30 \%$ hatching rate). 


\section{DISCUSSION AND CONCLUSIONS}

The ability to reproduce $P$. schmitti in captivity is of consideraile importance for commercial shrimp farms in Brazil, where this spevies shows the best growth among other foreign and native species in extensive cultivation (Nascimento and Ferreira de Souza, 1986). While some shrimp farms are presently maturing and reproducing $P$. schmitti indoors, the results in terms of postlarval production are still inconsistent and unpredictable, especially during the rainy periods (Nascimento and Ferreira de Souza, 1986). With steadily increasing demand for Penaeus schmitti fry for stocking extensive areas of brackish water ponds, it is necessary to overcome problems arising from poor-quality water supply. The present study documents attempts to reproduce $P$. schmitti in a seawater recirculating system where environmental conditions were relatively stable (Beard et al., 1977).

Most previous studies with open-thelycum species have shown enhanced maturation after removal of one eyestalk (Aquacop, 1975, 1979; SEAFDEC, 1976; Lawrence et al., 1980) even though species such as $P$. stylirostris, $P$. vannamei and $\boldsymbol{P}$. setiferus spawn naturally as a response to environmental conditions (Brown et al., 1979; Chamberlain and Lawrence, 1981). In this study, ablation of one eyestalk resulted in maturation of $P$. schmitti within 4 days in each of the three treatments, while unablated females took longer to develop their ovaries. Similarly, Aquacop (1980) reported that after ablation, a female $P$. monodon would develop full ovaries as early as 3 days after ablation, or as long as 3 to 4 weeks later. Lawrence et al. (1980) reported that spawning began 5 days after ablation.

In this study, eyestalk ablation of $\boldsymbol{P}$. schmitti did not cause decreased survival or spawn size. While for some penaeids, average egg numbers and hatching rates were higher for unablated females as compared to ablated females (Beard and Wickins, 1980; Emmerson, 1980, 1983), for others no differences were found (Alikunhi et al., 1975; Browdy and Samocha, 1985). It was suggested that the increased bioenergetic demand after ablation could cause a decrease in fecundity. According to Browdy and Samocha (1985), ablation of $P$. semisulcatus does not have any effect on spawn size or quality.

Our research showed a significant reduction in the frequency of spawning with time, for both ablated and unablated females. Emmerson (1980) found that $P$. indicus females, that spawned repeatedly, lost condition and died. After the first 15 day's of the present experiment, the shrimp were handled daily for monitoring individuals, which may have had a negative effect on maturation and spawning frequency. However, Aquacop (1979) reported that high-quality spawns were obtained from ablated $P$. monodon for 2 months after ablation.

In our experiment, eggs/female varied from 10000 to 342000 . Even though the number of eggs from unablated females averaged slightly higher, the difference was not significant $(P>0.05)$. Santiago (1977) found that egg num- 
bers from ablated female $P$. monodon are similar to those from gravid females in the wild. However, for oiner species such as $P$. merguiensis. Nurjana and Yang (1976) showed that fecundity of ablated spawners was much less than that of intact females.

Numbers of spawned eggs vary according to species size and individuals and are difficult to compare. According to Browdy and Samocha (1985), the effect of unilateral eyestalk ablation on spawn size and quality is poorly understood. Primavera et al. (1980) found no difference in spawn size from ablated and unablated $P$. indicus. Chamberlain and Lawrence (1981) observed that ablated $P$. stylirostris produced significantly more eggs per spawn than unablated females. Aquacop (1979) found 60000 to 200000 eggs from Penaeus vannamei of 30-45-g size and 70000 to 100000 from Penaeus stylirostris of $30-40-\mathrm{g}$ size. The average numbers found for $P$. schmitti in our research are within these ranges (from.139812 to $199500 \mathrm{eggs} / \mathrm{spawn}$ ).

Significant differences in maturation (as evidenced by the occurrence of stage-IV ovaries), spawning, fecundity, tuating and molting rates of $P$. schmitti were obtained as a result of the different diets used. For maturation, spawning and fecundity, the best results were obtained with $100 \%$ dried formulated feed, followed by, but not significantly different from the mixed diet ( $50 \%$ fresh-frozen and $50 \%$ dried formulated food), while for mating and molting rates, the mixed diet followed by, but not significantly different from the freshfrozen food, gave the highest values. Considering the relative importance of all these phenomena for reproduction, we conclude that the mixed diet led to the best general results. This agrees well with published information on reproduction of penaeids, which shows that best results are obtained when using some combination of food types (Beard et al., 1977; Santiago, 1977; Lumare, 1979; Beard and Wickins, 1980). Primavera et al. (1979), working with $P$. monodon and using only pelletized food, succeeded in achieving reproduction when fresh food was offered together with dried formulated feed. According to Lawrence et al. (1980), P. setiferus spawned and hatched when one third of the fresh-frozen diet was replaced with a prepared diet.

Diet also influenced molting in $P$. schmitti. The dried formulated food produced the lowest molting rate. The relationship between molting and mating for shrimp is well known. Males of open-thelycum species transfer the spermatophore after ovarian development and just before spawning, generally during the intermolt phase (Hanson and Goodwin, 1977). Males of closedthelycum species transfer the spermatophore just after molting but before ovarian development. Closed-thelycum females carry the sperm until they molt or until the ovaries develop and spawning takes place (Mcore et al., 1974; Aquacop, 1975, 1976; Laubier-Bonichon and Laubier, 1976; SEAFDEC, 1976; Santiago, 1977). The periodicity of the molting process has been reported for many species, both ablated and unablated (Arnstein and Beard, 1975; Aquacop, 1979; Browdy and Samocha, 1985). With the exception of 
Aquacop (1975), where a brief reference is made to existence of a lunar periodicity relating moltings and spawnings in $P$. merguiensis, no reference has been found describing the effect of the lunar cycle on the alternating occurrence of moltings and matings in the white shrimp. Although this study only spanned two lunar cycles, correlation analysis showed that mating peaks consistently occurred around the full and new moons, while molting peaks occurred predominantly in the intervals between. No mating occurred during the molting peaks. These phenomena were highly correlated with the lunar cycle, a fact that supports the advice not to check the females for mating around full and new moon phases. This would avoid excessive stress and probably promote a longer utilization of the same broodstock.

\section{ACKNOWLEDGEMENTS}

The first author is indebted to CAPES/FULBRIGHT Comission (Brazil) which provided a posidoctorate fellowship and to Dr. Donald Henry Smith for statistical analysis and reviewing of the manuscript.

\section{REFERENCES}

Alikunhi, K.H., Poernomo, A., Adisukresno, S., Budiono, M. and Busman, S., 1975. Preliminary observations on the induction of maturity and spawning in $P$. monodon Fabricius and $P$. merguiensis de Man by eyestalk extirpation. Bull. Shrimp Cult. Res. Cent., $1(1): 1-11$.

Aquacop, 1975. Maturation and spawning in captivity of penaeid prawns $P$. merguiensis de Man, $P$. japonicus Bates, P. aztecus Ives, Metapenaeus ensis de Haan and P. semisulcatus de Haan. Proc. World Maricult. Soc., 6: 123-132.

Aquacop, 1976. Reproduction in captivity and growth of Penaeus monodon Fangricius in Polynesia. Proc. World Maricult. Soc., 8: 927-945.

Aquacop, 1979. Penaeid reared broodstock: closing the cycle of $P$. monodon, $P$. stylirostris and P. vannamei. Proc. World Maricult. Soc., 10: 445-452.

Aquacop, 1980. Rearing broodstock of $P$. monodon. Proc World Maricult. Soc., i i: 352-363.

Arnstein, D.R. and Beard, T.W., 1975. Induced maturation of prawn $P$. orientalis Kishinouye in the laboratory by means of eyestalk removal. Aquaculture, 5: 411-412.

Beard, T.W. and Wickins, J.F., 1980. Breeding of $P$. monodon Fabricius in laboratory recirculation systems. Aq aculture, 20: 79-89.

Beard, T.W., Wickir's. J.F. and Arnstein, D.R., 1977. The breeding and growth of $P$. merguiensis de Man in laboratory recirculation systems. Aquaculture, 10: 275-289.

Browdy, C.L. and Samocha, T.M., 1985. The effect of eyestalk ablation on spawning, molting and mating of $P$. semisulcatus de Haan. Aquaculture, 49: 19-20.

Brown, A., Jr., McVey, J., Middleditch, B.S. and Lawrence, A.L., 1979. Maturation of white shrimp (Penaeus setiferus) in captivity. Proc. World Maricult. Soc., 10:435-444.

Chamberlain, G.W. and Lawrence, A.L., 1981. Maturation, reproductiun and growth of $P$. vannamei and $P$. stylirostris fed natural diets. Proc. 12th Annu. Meet. World Maricult. Soc., 1: 209-224.

Emmerson, W.D., 1980. Induced maturation of prawn Penaeus indicus. Mar. Ecol. Prog., Ser., 2: $121-131$. 
Emmerson, W.D., 1983. Maturation and growth of ablated and unablated $P$. monodon Fabricius. Aquaculture, 32: 235-241.

Hanson, J.A. and Goodwin, H.L., 1977. Shrimp and Prawn Farming in the Western Hemisphere. State of Reviews and Status Assessment. Dowden, Hutchinson and Ross, Stroudsburg, PA, USA, 439 pp.

Kelemec, J.A. and Smith, I.R., 1980. Induced ovarian development and spawning of $P$. plebejus is a recirculating laboratory tank after unilateral eyestalk enucleation. Aquaculture, $21: 55-$ 62.

King, J.E., 1948. A study of the reproductive organs of the common marine shrimp, $P$. setiferus (Linnaeus). Biol. Bull., 94: 244-262.

Laubier-Bonichon, A. and Laubier, L., 1976. Controlled reproduction of Penaetis japonicus shrimp. In: FAO Tech. Conf. Aquacult., Kyoto, Japan, 26 May-2 June, pp. 1-6.

Lawrence, A.L., Akamine, Y, Middleditch, B.S., Chamberlain, G. and Hutchins, D., 1980. Maturation and reproduction of $P$. setiferus in captivity. Proc. 1 th Annu. Meet. World Maricult. Soc., pp. 481-487.

Lichatowich, T.S., Malley, T. and Mate, F.D., 1978. The natural reproduction of $P$. merguiensis (de Man, 1888) in an earthen pond in Fiji. Aquaculture, 15: 377-478.

Lumare, F., 1979. Reproduction of $P$. kerathurus using eyestalk ablation. Aquaculture, 18: 203214.

Moore, D.W., Sherry, R.W. and Montanez, F., 1974. Maturation of $P$. californiensis in captivity. In: Proc. Annu. Workshop World Maricult. Soc., Charleston, SC, 27-26 Jan., pp. 445449.

Nascimento, I.A. and Ferreira de Souza, T.P., 1986. Presente "Status" do cultivo de camarões Peneídeos no Brasil. I Simpósio Internacional sobre cultivo de camarões. Salvador, Bahia, Brasil, October 1986, 23 pp.

Nic, N.H., Hull, C.H., Jenkins, J.G., Steinbrenner, K. and Bent, D.H., 1975. SPSS-Statistical Package for the Social Sciences, 2nd edn. Mc Graw-Hill, New York, NY, 675 pp.

Nurjania, M.L. and Yang, W.T.. 1976. Induced maturation, spawning and post-larval production of $P$. merguiensis de Man. Bull. Shrimp Cult. Res. Cent. Japara, $(1+2): 177-186$.

Primavera, J.H., 1978. Induced maturation and spawning in five-month-old Penaeus monodon Fabricius by eyestalk ablation. Aquaculture, 13: 355-359.

Primavera, J.H., Lim, C. and Borlongan, E., 1979. Effect of different feeding regimes on reproduction and survival of ablated Penaeus monodon Fabricius. Southeast Asian Fish. Dev. Cent. Aquacult. Depart. Q. Res. Rep., 3: 12-14.

Primavera, J.H., Young, T. and De Los Reyes, C., 1980. Survival, maturation, fecundity and hatching rates of unablated and ablated $P$. indicus H.M. Edwards, from brackish ponds. Contrib. 59. Int. Symp. Coast. Aquacult., 12-18 Jan., Cochin, India. Southeast Asian Fish. Dev. Cent. Aquacult. Depart., Philippines, 14 pp.

San Feliu, J.M., 1987. Influencia de la temperatura, fotoperiod, alimentacion y ablacion unilateral del pedunculo ocular en la maturacion de P. keratus. Cuad. Marisc. Publ. Tech., 12: 273278.

Santiago, A.C., Jr., 1977. Successful spawning of cultured $P$. monodon Fabricius, after eyestalk ablation. Aquaculture, 11: 185-196.

SEAFDEC Prawn Maturation Team, 1976. Development of a broodstock of the tiger prawn $P$. monodon Fabricius. Tech. Rep., 1, 10 pp. 